\title{
Nanocellulose from fractionated sulfite wood pulp
}

\author{
Armin Winter (1) - Benjamin Arminger - Stefan Veigel • Claudia Gusenbauer • \\ Wolfgang Fischer $\cdot$ Melanie Mayr $\cdot$ Wolfgang Bauer $\cdot$ Wolfgang Gindl-Altmutter
}

Received: 9 October 2019/Accepted: 29 August 2020/Published online: 15 September 2020

(C) The Author(s) 2020

\begin{abstract}
Fine fibre fractions in wood pulp may contribute to advantageous paper properties, but in some instances their removal from pulp may be beneficial to the production process of certain paper grades. In order to study the suitability of fine fibre fractions for the production of nanocellulose as an alternative use option, sulfite pulp was fractionated and homogenised, and cellulose nanopapers were produced. Characterisation revealed that fine fibre fractions were more easily homogenised than long
\end{abstract}

Electronic supplementary material The online version of this article (https://doi.org/10.1007/s10570-020-03428-8) contains supplementary material, which is available to authorized users. fibres. Aqueous suspensions of nanocellulose produced from fines showed remarkably reduced viscosity compared to nanocellulose derived from long fibres. Nanopapers produced from all nanocellulose variants showed roughly similar mechanical performance. Only nanopaper produced from primary finesderived nanocellulose deviated in that it showed a comparably high modulus of elasticity at a low strain at failure. Overall, fine fibre fractions separated from wood pulp were found to be highly suitable for nanocellulose production.

M. Mayr

Mondi GmbH, Theresiensthalstr. 50, 3363 Hausmening, Austria

\section{W. Bauer}

Institute of Bioproducts and Paper Technology, NAWI Graz, Graz University of Technology, Inffeldgasse 23, 8010 Graz, Austria

\section{B. Arminger}

Wood K Plus - Competence Centre for Wood Composites and Wood Chemistry, Konrad-Lorenz-Straße 24, 3430 Tulln, Austria

W. Fischer

Sappi Paper GmbH, Brucker Str. 21, 8108 Gratkorn, Austria 
Keywords Cellulose nanofibrils · Primary/ secondary fines $\cdot$ Sulfite pulp $\cdot$ Microfibrillation . Morphology $\cdot$ Rheology

\section{Introduction}

Since more than one decade, nanocellulose has been a topic of high relevance to the scientific community and the pulp and paper industrial sector (Charreau et al. 2013; Dufresne 2013; Eichhorn et al. 2010; Klemm et al. 2018; Klemm et al. 2011; Li et al. 2015; Oksman et al. 2016; Thomas et al. 2018). The term nanocellulose comprises the sub-groups of cellulose nanofibrils (CNFs) and cellulose nanocrystals (CNCs). While the major processing step in CNF production is mechanical fibrillation of cellulosic raw materials to high-aspect ratio nanofibres with diameters $<100 \mathrm{~nm}$, the key process in CNC synthesis involves the digestion of non-crystalline cellulose by means of strong acids, resulting in highly crystalline cellulose nanorods. Owing to the high specific surface area and mechanical strength of nanocellulose, a manifold of opportunities for application arises.

The reinforcement of polymeric matrices with nanocellulose suggests itself as an obvious application of nanocellulose, but lack of control over fibril orientation, insufficient surface-chemical fibre-matrix compatibility, the need for processing in wet condition, and the question of scalability still prevent a large-scale break-through in this field (Ansari and Berglund 2018; Kargarzadeh et al. 2018; Lee et al. 2014; Oksman et al. 2016). Porous nanocellulosebased materials (De France et al. 2017; Long et al. 2018) represent a second large class of potential applications. Also, for these materials the challenge of scalable dewatering and drying methods towards industrialisation of production is substantial.

In contrast to polymer reinforcement and porous materials as two major routes of application, the use of nanocellulose as a functional additive in paper and similar materials seems to present less technological hurdles as wet processing is the norm in papermaking (Boufi et al. 2016; Osong et al. 2015). Within the major classes of nanocellulose materials, i.e. polymer composites, porous materials, and paper-like materials, there is an extreme diversity of potential applications studied.
To name just a selection based on recently published studies, nanocellulose applications are being studied in biomedical applications ( $\mathrm{Du}$ et al. 2019; Dumanli 2017), supercapacitors (Xing et al. 2019; $\mathrm{Zu}$ et al. 2016), 3D printing (Dai et al. 2019; Siqueira et al. 2017; Xu et al. 2018), flexible-hybrid printed electronics and conductive composites (Agate et al. 2018), packaging (Bharimalla et al. 2017; Ferrer et al. 2017; Gan and Chow 2018), or luminescent and transparent films (Yang et al. 2018). With ongoing progress towards the realisation of applications, the question of suitable raw material resources for the production of nanocellulose comes to the fore.

While basically any cellulose-containing resource can be successfully converted to nanocellulose, different groups of resources are characterised by individual sets of advantages and disadvantages (Phanthong et al. 2018; Rajinipriya et al. 2018). Nanocellulose was successfully produced from foodindustrial sidestreams such as sugar beet pulp (Hietala et al. 2017; Leitner et al. 2007), residues of fruit juice production (Cypriano et al. 2018), or spent beer brewing grains (Shahabi-Ghahafarrokhi et al. 2015), and residues from biogas- and bioethanol production may be valorised by nanocellulose extraction (Henniges et al. 2014; Mathew et al. 2014). Notwithstanding the importance of non-woody resources for nanocellulose production, the most relevant and continuously available resource of cellulosic fibre is wood pulp (Dufresne 2013; Siddiqui et al. 2011) with fibres being the main component in a pulp suspension.

According to ISO 16065-2 (ISO 2014), they are defined as all particles in the pulp furnish with a length larger than $200 \mu \mathrm{m}$, consisting of a lumen and a fibre wall. The second fibrous component of a pulp suspension is termed fines. Papermaking fines are defined as the pulp fraction which passes through a 200 mesh $(76 \mu \mathrm{m})$ screen (Odabas et al. 2016). Primary fines are those fines present already after the pulping process and mainly consist of ray cells, parenchyma cells, fragments of the middle lamella and only a small portion of fibrils, whereas secondary fines contain fibrillated (microfibrillar) and lamellar material (microfibril bundles) originating from the fibre wall, as a result of mechanical forces acting on a fibre during beating (Hyll 2015). Related to their origin, primary fines contain more lignin and extractives as well as a higher carboxyl group content and consequently less cellulose (Odabas et al. 2016). Also 
secondary fines, sheared off the fibre during beating from the outermost lignin rich primary wall and S1 layer show a higher lignin and extractives content compared to the fibre fraction (Odabas et al. 2016). Higher lignin content may be of relevance e.g. with regard to the thermomechanical properties of fines (Tao et al. 2019; Zhang et al. 2018; Zhang et al. 2019).

As a component of paper, sheets containing primary fines show lower strength properties compared to sheets containing the same quantity of secondary fines (Fischer et al. 2017). Also films of pure primary or secondary fines fractions show this behaviour related to the fact that secondary fines are more flexible, have a higher specific surface area and therefore a higher bonding ability. Furthermore, the high specific surface area of fines compared to regular paper fibres may disproportionately contribute to consumption of bleaching and wet end chemicals and impair dewatering of the suspension during papermaking. Thus, while beneficial to certain paper grades, removal of fines from production lines not positively affected by fines may be of interest, opening up the possibility of valorisation beyond papermaking. As shown for spray-dried powder (Colson et al. 2017), oil-absorbing porous materials (Colson et al. 2018), and paper handsheets (Bossu et al. 2019; Fischer et al. 2017), papermaking fines show some similarity in performance to CNFs.

Furthermore, pre-fractionation of the pulp and subsequent fibrillation of the primary fines can be useful to facilitate the implementation of CNF derived products. This can only be ensured under the prerequisite that the performance of the resulting CNFs is comparable with CNFs produced from unfractionated pulp. The grinding of cellulose into microfibrillated cellulose (MFC) and further into CNFs has been known since the early $1980 \mathrm{~s}$ (Turbak et al. 1983). Since then the comparably high energy demand (Spence et al. 2011; Tejado et al. 2012) of CNF production impedes applications in industry. Fines fractionation from wood pulp and ensuing fibrillation may be economically advantageous because it benefits the main product by eliminating undesired fines fractions and generates additional value from CNFs produced thereof.

Thus, the question arises whether papermaking fines may be converted into CNFs showing performance comparable to CNFs derived from standard wood pulp. Since this question has not been addressed in literature to the knowledge of the authors, the question whether individual fractions exhibit advantageous characteristics when used as a raw material for CNF production will be evaluated in the present study. A fractionation device is used to isolate fibres and fines fractions from sulfite pulp and produce CNFs from all these fractions, which will then be compared according to their suitability for $\mathrm{CNF}$ production.

\section{Experimental}

Preparation of pulp fractions and CNFs

Never-dried bleached sulfite pulp (90\% spruce, $10 \%$ beech, magnefite process) with a kappa number of 6 was supplied by Sappi, Gratkorn. It was used as basis material for reference, fractionation and grinding experiments. The unrefined pulp samples were fractionated at approximately $1 \%$ solids content, using a lab-scale pressure screen (Fischer et al. 2017), in order to separate the fibre fraction from the fines fraction. This pressure screen was equipped with a perforated plate (hole diameter $100 \mu \mathrm{m}$ ). The material passing through this plate was defined as the primary fines fraction and collected in a separate tank. The pulp was recirculated until the remaining volumetric fines content (measured with an L\&W Fiber Tester Plus, ABB) was below $0.5 \%$. This fraction was defined as the fibre fraction. The fines were allowed to settle for three days, before the supernatant was removed and approximately $1 \%$ solids content was reached. Fibres were centrifuged to approximately $30 \%$ consistency.

Secondary fines were produced by refining (grinding) a part of the fibre fraction (after the removal of the primary fines) in a Valley Beater. The obtained material containing refined fibres and secondary fines was also fractionated with the lab-scale pressure screen, identically to the procedure described for the isolation of primary fines above.

For the preparation of CNFs, each type of fibre suspension was ground five times with a solid content of $0.5 \%$, using a Masuko supermasscolloider MKCA6-2J CE (Masuko Sangyo Co., Ltd, Japan) at $1500 \mathrm{rpm}$ and $-50 \mu \mathrm{m}$ nominal gap clearance. Grinding was necessary in order to ensure passage of long fibres through the homogeniser in the following homogenisation process. Fibrillation was carried out in an SPX APV 1000 homogeniser (SPX Corporation, 
USA). For each pass through the homogeniser, the pressure on the homogenisation valve was increased gradually, starting with zero nominal pressure, then 10, 20, and $40 \mathrm{MPa}$. Thereafter, a pressure of $80 \mathrm{MPa}$ was applied for every pass, considering the first pass at $80 \mathrm{MPa}$ as pass number 1 . All variants were homogenised for up to 20 passes (80 MPA). The solids content of the suspension gradually increased due to evaporation of water. Hence, for the following viscosity measurements the solid content was redetermined and if necessary the sample was diluted back to its original value of $0.5 \%$.

Table 1provides a summary of the materials and nomenclature used

\section{Characterisation}

For light microscopy, fibre suspensions were treated with gential violet stain (methylrosanilinium chloride, Sigma-Aldrich) and observed in transmitted light mode using glass slides and cover slips. Pulp fibre dimensions and shape were examined by means of an L\&W Fiber Tester Plus (ABB / Lorentzen \& Wettre, SWE) having a resolution of $3.3 \mu \mathrm{m} /$ pixel. For each measurement, $200 \mathrm{ml}$ suspension of $0.1 \%$ fibres in deionised water was prepared. The measurement was carried out for a maximum duration of $10 \mathrm{~min}$ and aborted earlier in cases where a threshold of 300.000 particles measured was surpassed. Two independent replicates of each sample were measured, followed by a washing step with $350 \mathrm{ml}$ of distilled water. While the geometry of regular pulp fibres is described in a straightforward manner using parameters such as fibre length and diameter, pulp fines are often of irregular geometry and consist of aggregates of smaller fibre fractions. Therefore, fibre geometry was expressed as the average circle equivalent diameter (CED), which can be used instead of the length weighted average particle length (Fischer et al. 2017; Mayr et al. 2017). The CED is the diameter of a circle whose area is equivalent to the projected area of an irregularly shaped particle or fibril aggregate.

The viscosity of suspensions of the four homogenised fibre variants was measured using a CS50 cone and plate rheometer (Bohlin Instruments). The cone diameter was $40 \mathrm{~mm}$, cone angle $4^{\circ}$, and the truncation gap $150 \mu \mathrm{m}$. For each measurement, $1.5 \mathrm{ml}$ of suspension containing $0.5 \%$ fibres was placed on the plate with a syringe. Measurements were performed at a constant shear rate of $20 \mathrm{~s}^{-1}$ and constant temperature of $20^{\circ} \mathrm{C}$.

Mechanical characterisation was carried out with thin nanopapers produced from suspensions that were homogenised 20 times. A $100 \mathrm{~mm}$ diameter Büchner funnel equipped with a $90 \mathrm{~mm}$ diameter polycarbonate membrane filter type $0.2 \mu \mathrm{m}$ (Isopore ${ }^{\mathrm{TM}}$ ) was placed on top of a vacuum flask, connected via an elastomer bung. The flask was attached to a vacuum pump with an ultimate vacuum of $80 \mathrm{~Pa}$. An aliquot of fibril suspension corresponding to $0.5 \mathrm{~g}$ dry fibril mass was poured into the funnel and vacuum applied until a transportable fibre mat was formed on top of the filter paper. For the next step, another $90 \mathrm{~mm}$ diameter polymer filter was placed on top of the fibre mat to avoid sticking during further drying. The mat was then put in between a $240 \mathrm{~mm}$ diameter carrier carton and a

Table 1 Nomenclature and material description

\begin{tabular}{ll}
\hline Nomenclature & Description \\
\hline Original Pulp & Untreated never dried sulfite pulp \\
Long fibres & Long fibre fraction $>\sim 100 \mu \mathrm{m}$, originated from never dried sulfite pulp \\
Primary fines & Short fibre fraction $<\sim 100 \mu \mathrm{m}$, originated from never dried sulfite pulp \\
Secondary & Mechanical fibrillated and subsequent fractionated fibre fraction $<\sim 100 \mu \mathrm{m}$ originated from never dried sulfite \\
$\quad$ fines & pulp \\
H0 & Prefix for material without further defibrillation \\
H5 & Prefix for material treated with one grinding step, three homogenisation steps with 10,20 and $40 \mathrm{MPa}$, and five \\
& homogenisation steps with $80 \mathrm{MPa}$ \\
H20 & Prefix for material treated with one grinding step, three homogenisation steps with 10,20 and $40 \mathrm{MPa}$, and 20 \\
& homogenisation steps with $80 \mathrm{MPa}$ \\
\hline
\end{tabular}


$205 \mathrm{~mm}$ diameter cover sheet (both sheet formation equipment of PTI). This layered structure was exposed to vacuum and heat inside the drying unit of a RK-1 $\mathrm{h}$ laboratory sheet former (Rapid-Köthen / PTI). Drying time depends on the fibre mat's water content after filtration and was about $20 \mathrm{~min}$. Uneven sheets were smoothened using a conventional iron and a spray of distilled water. By means of a razor blade parallel strips with a width of $5 \mathrm{~mm}$ and a length of about $80 \mathrm{~mm}$ were cut out of the nanopaper sheets. Prior to testing the samples were conditioned at $23{ }^{\circ} \mathrm{C}$ and $50 \%$ r.h. until equilibrium moisture content was reached. Tensile tests were performed with these strips on a universal testing machine Zwick/Roell Z020. The clamping length was $25 \mathrm{~mm}$ and samples were strained at a rate of $1 \mathrm{~mm} \mathrm{~min}{ }^{-1}$. The sample deformation was characterised via crosshead displacement without the use of an extensometer. Modulus of elasticity was determined by linear regression in the range of $10-40 \%$ of the maximum applied load. The criterion for ending the tests was set at an $80 \%$ load drop.

Microscopic characterisation of the nanopaper sheets was carried out by means of scanning electron microscopy (SEM) and atomic force microscopy (AFM). For SEM, a Qanta 250 FEG electron microscope (FEI, USA) was used. The nanopapers were sputter coated for $2 \mathrm{~min}$ by $1500 \mathrm{~V}$ to obtain a thin gold layer, enhancing conductivity and image resolution of the obtained pictures. The surface morphology was scanned with a $20 \mathrm{kV}$ electron beam.

A Dimension Icon AFM equipped with a Scanasyst Air cantilever (Bruker, USA) was used to obtain highresolution topography images of the surface of the nanofibers and nanopapers. The nominal radius of the silicon tip was $2 \mathrm{~nm}$. Measurements were performed at ambient conditions and post-processing was carried out using Gwyddion 2.42 software. The fibre diameter was expressed as geometric mean by measuring 15 individual fibril diameters per variant.

\section{Results and discussion}

Light microscopy of fibre suspensions shown in Fig. 1 reveals differences in morphology between the four variants of raw materials used and demonstrates the effect of homogenisation. While the original pulp used as a base material for the entire study consists of long fibres and a small fraction of fines, the fines fraction is very efficiently removed during fractionation, as highlighted by the "clean" appearance of the washed long fibre fraction shown in Fig. 1. With regard to the primary and secondary fines fractions, the overall qualitative impression is that, primary fines consist of a fibrillar fraction, but larger non-fibrillar fragments with diameters $>1 \mu \mathrm{m}$ are also present in significant amounts (in the context of the present study, those parts of a fibre suspensions whose diameter cannot be clearly resolved in the light microscope, i.e. well below $1 \mu \mathrm{m}$, are termed fibrils or fibrillar). By contrast, the overall tendency in secondary fines is that fibrillar material dominates, even though a small amount of larger fragments may also be found.

In order to confirm nano-scale fibrillation, light microscopy was supplemented with AFM (Fig. 2). Clearly, nanofibrils are abundant after 20 homogenisation cycles, with geometric diameters in the order of $10-13 \mathrm{~nm}$. It should be emphasized that these measurements reflect only a limited part of the fibrils and do not allow any conclusion about the whole population. For the exact measuring points, the reader is referred to the supplementary material.

This visual and only qualitative impression is supported by quantitative results obtained by means of automated fibre sized measurement in a Fiber Tester Plus. Due to the highly efficient removal of fines, the CED averaged over all fibres characterised is highest for the long fibre fraction with $290 \mu \mathrm{m}$ compared to a value of $230 \mu \mathrm{m}$ (Fig. 3) for the original pulp. By contrast, with values close to $50 \mu \mathrm{m}$ the average CED is significantly smaller for both fines fractions isolated from the original pulp. The frequency distribution of different CED values of the original pulp and fractions derived thereof provides more detailed insights (Fig. 4). In the original and untreated pulp long fibres with CED in the range between 100 and $500 \mu \mathrm{m}$ are detected together with a significant proportion of fines with CED $<100 \mu \mathrm{m}$ (Fig. 4a). While the fraction of elements with large CED remains unchanged after fractionation, the fines portion is completely removed in the long fibre fraction (Fig. 4b). As to the primary and secondary fines fractions, whose average CED is 52 and $55 \mu \mathrm{m}$, respectively, a tendency towards very small CED is observed in primary fines compared to secondary fines (Fig. 4c-d). 


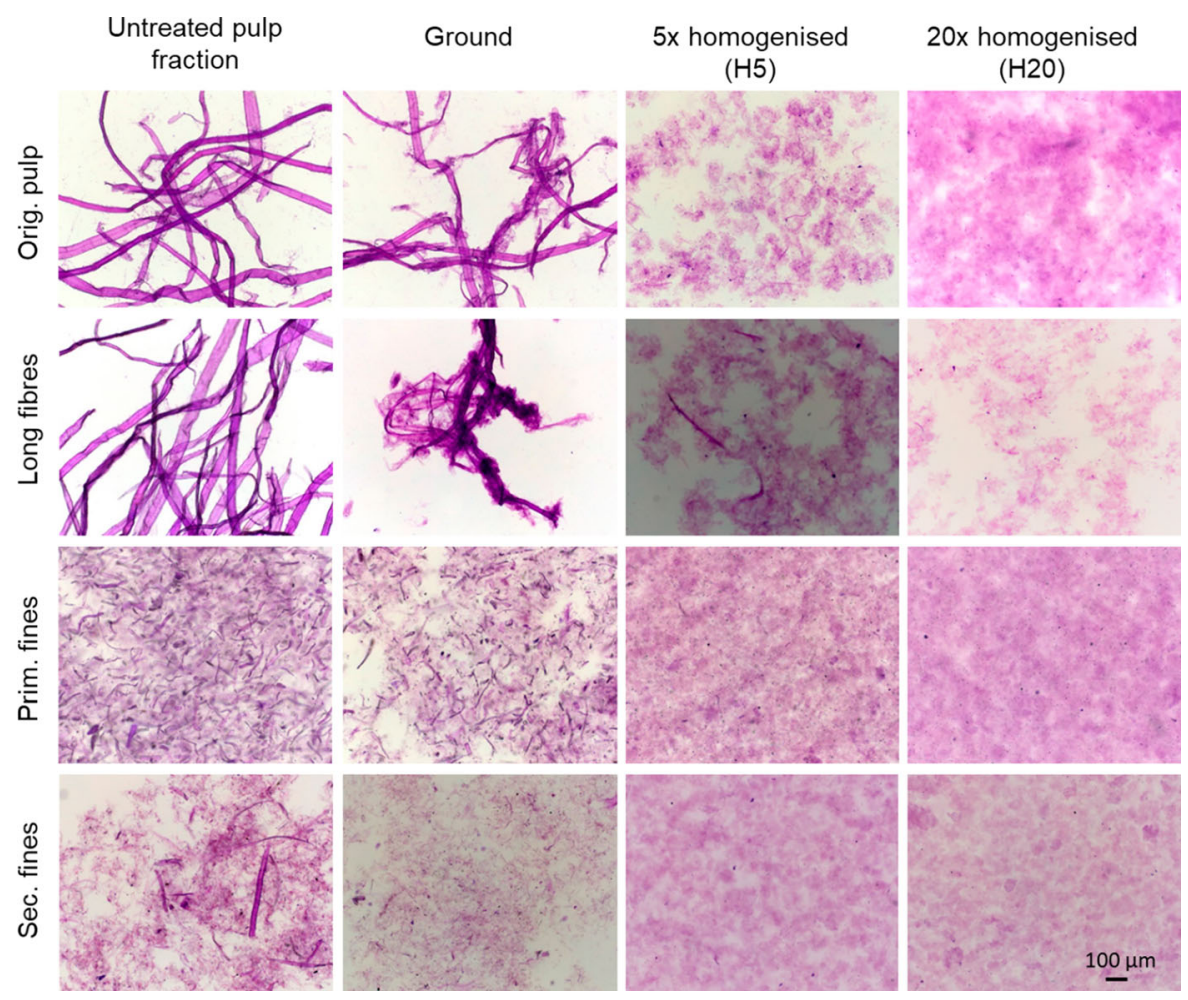

Fig. 1 Light microscopy of original pulp and fractions thereof in untreated and grinded/homogenised condition. with specified averaged geometric mean values (the same scale applies to all images)

Orig. pulp

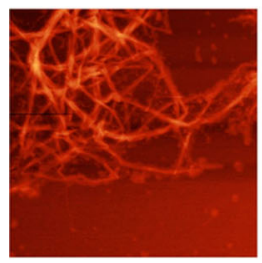

$\overline{\mathrm{x}}_{\mathrm{geom}}=10.2 \mathrm{~nm}$
Long fibres

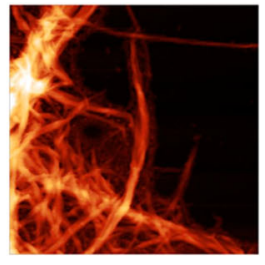

$\overline{\mathrm{x}}_{\text {geom }}=12.3 \mathrm{~nm}$
Prim. fines

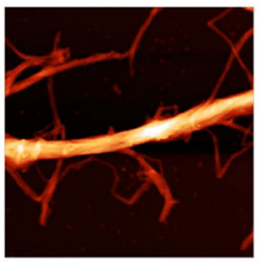

$\overline{\mathrm{x}}_{\text {geom }}=13.0 \mathrm{~nm}$
Sec. fines

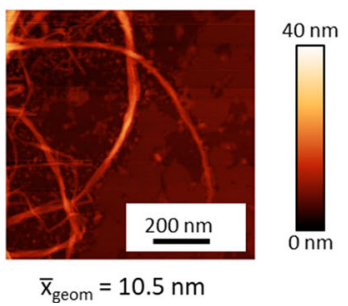

Fig. 2 AFM images of CNFs derived from pulp fractions treated by 20 homogenisation cycles with averaged geometric mean values of fibril diameters, $\mathrm{n}=15$ (the scale applies to all images)

Starting from the original pulp and the three fractions derived thereof, different mechanical treatments were applied. A grinding step proved necessary in order to avoid clogging of the homogeniser with long fibres. Grinding changed the optical appearance of the original pulp and the long fibre fraction towards more fibrillation (Fig. 1). Fibres appeared to be fibrillated on their surface, but remained intact in their overall size i.e. they were not completely broken down into fibrils by this treatment step. While the optical appearance was not noticeably affected by grinding, some larger fragments seemingly were broken down to fibrillar elements in secondary fines. In contrast to five passes to the Masuko grinder, the same number of passes through the high-pressure homogeniser resulted to a complete breakdown of fibre structure in terms of fibrillation as revealed by light microscopy (Fig. 1), AFM (Fig. 2) and characterisation in the Fibre Tester (Figs. 3 and 4). In all four fibre variants CED shifts towards smaller values and large elements in the original pulp and long fibre fractions are diminished. Accomplishing 5 passes for the fines 


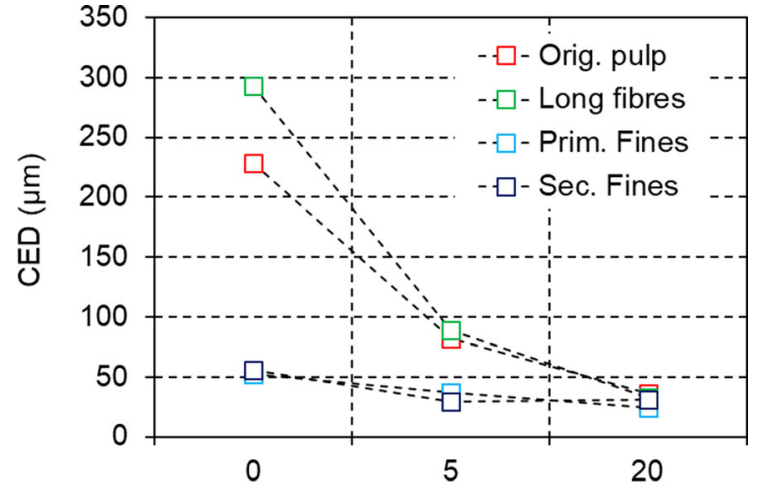

Number of homogenisation passes

Fig. 3 Average circle equivalent diameter (CED) of original pulp and fractions thereof in untreated and homogenised condition

fractions the CED values are overall below $100 \mu \mathrm{m}$ (Fig. 4c, d), while for original pulp and long fibre fraction the observed CED values are divided over an area below $250 \mu \mathrm{m}$. Although no fines are contained in the long fibre fraction, compared to the original pulp the CED values are both very similar after 5 passes which could be explained by defibrillation occuring predominantly on long fibres before smaller aggregates get further reduced (Fig. 4a, b). After 20 passes through the homogeniser, the average CEDs of three pulp fractions, i.e. original pulp, long fibres and secondary fines, approach similar values in a range between roughly 31 and $36 \mu \mathrm{m}$ (Fig. 3). In case of secondary fines, the CED alteration through defibrillation diminishes after 5 passes. In contrast, primary fines show the smallest CED values around $24 \mu \mathrm{m}$. With regard to the frequency distribution of CED, primary fines show a dominance of very small elements, whereas the frequency distribution pattern is of comparable shape for the remaining three variants (Fig. 4). Emphasizing that, primary fines contain besides fibrillar cellulosic material, flake like residues, which originates from different cell wall fragments, e.g. middle lamella and parenchyma cells. The defibrillation pattern of these fractions obviously differs

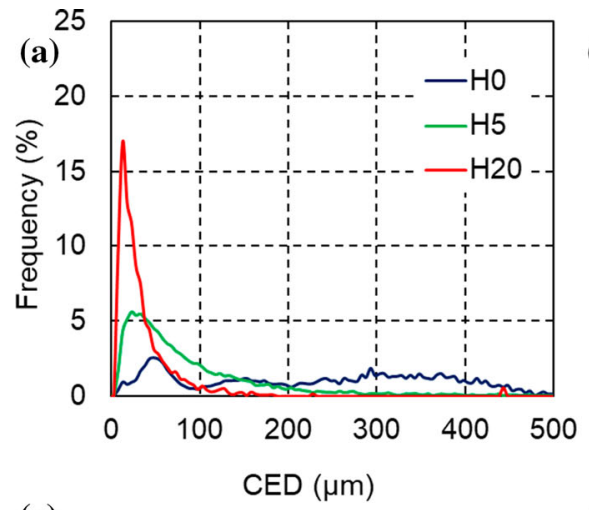

(c)

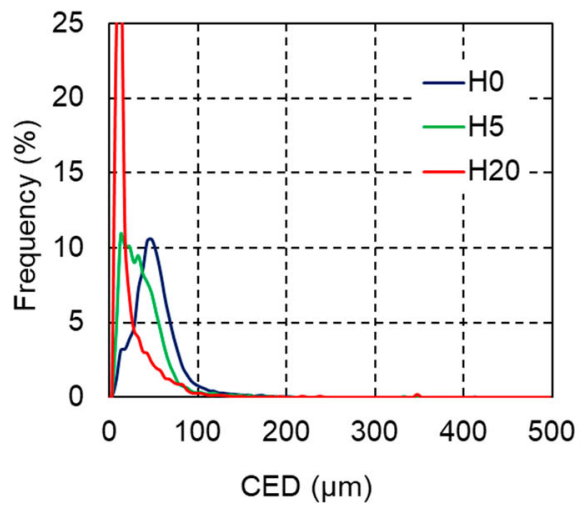

(b)

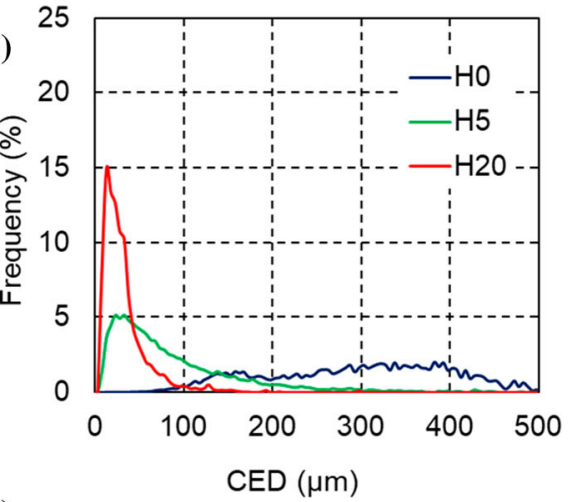

(d)

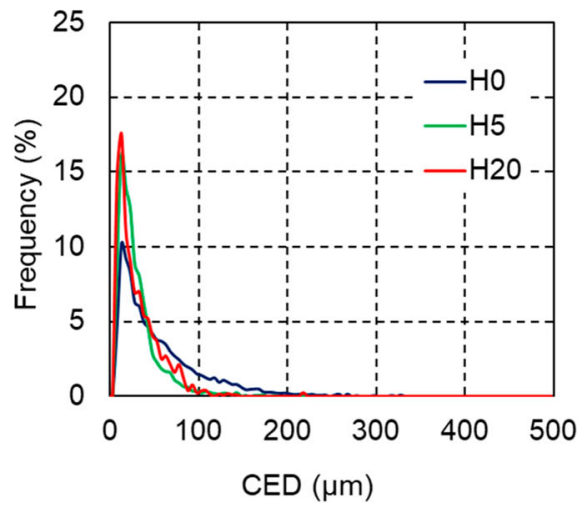

Fig. 4 Distribution of the circle equivalent diameter (CED) of a original pulp, $\mathbf{b}$ long fibres, $\mathbf{c}$ primary fines and $\mathbf{d}$ secondary fines in untreated (H0) and homogenised condition (H5 and H20, signifying 5 and 20 passes through the homogeniser, respectively) 
from that of cellulosic fibrillar material, ending in the smallest aggregates after 20 passes.

In parallel to the development of microscopic fibre morphology and fibre dimensions, the viscosity of fibre suspensions was monitored as an additional indicator of fibrillation (Desmaisons et al. 2017).

Flocculation is a critical factor in viscosity measurements, and therefore each measurement was carefully examined with regard to this phenomenon. Discarding all such measurements, meaningful viscosity data for the original pulp and long fibre fractions were obtained only after the 5th and 10th homogenisation pass, respectively (Fig. 5). By contrast, no flocculation was observed for the fines fractions at a low number of passes. When evaluating viscosity data, the clearest difference is evident between the fibre and the fines fractions. Both, original pulp and long fibres show significantly higher viscosity than both fines fractions. Two factors may be responsible for this clear difference. Firstly, even though the average size of fibril aggregates after 20 homogenisation passes expressed by CED is only slightly higher for fibres compared to fines (Fig. 3), longer and more slender CNFs may be generated by homogenisation of fibres compared to homogenised initially much smaller fines. The tendency of longer fibrils towards aggregation and network formation (Iotti et al. 2011) then results in higher viscosity of CNF suspensions derived from long fibres. Secondly, the trend towards higher lignin content in fines compared to fibres (Odabas et al. 2016) may lead to reduced adsorption of water to the fines surface, favouring reduced viscosity of finesderived CNF suspensions. In a similar study dealing with the evolution of viscosity of CNF suspensions produced from fibres, fines, and mixtures thereof (Colson et al. 2016) and in related studies (Grueneberger et al. 2014), a clear trend towards increasing viscosity with an increase in the number of homogenisation passes was observed. In the present study, no such trend is evident, partly because in the case of long fibres no valid data is available for low numbers of homogenisation passes (Fig. 5). As to the fines fractions, after an initial increase in viscosity, the viscosity of primary fines suspensions decreases steadily with increasing numbers of homogenisation passes, while a steadily decreasing viscosity over the whole range of homogenisation passes is observed for secondary fines. Here, one may speculate that progressing fibrillation of fines negatively affects the length of, initially already comparably short, fibrils, leading to reduced viscosity in suspension.

In order to evaluate the suitability of CNFs derived from different pulp fractions for application a structural material, thin nanopapers were produced and characterised. SEM images of nanopaper surfaces (Fig. 6) show a smooth appearance indicating thorough fibrillation. Here, only in the long fibre fraction unfibrillated larger fibres occasionally show up. While higher magnification did not reveal more detail for most fractions, the primary fines fraction was a notable exception. Here, numerous smooth platelets with size in the order of $2 \mu \mathrm{m}$ were found. It may be speculated that these platelets originate from the lignin rich middle-lamella/primary cell wall region. However, due to the low lignin content of the starting

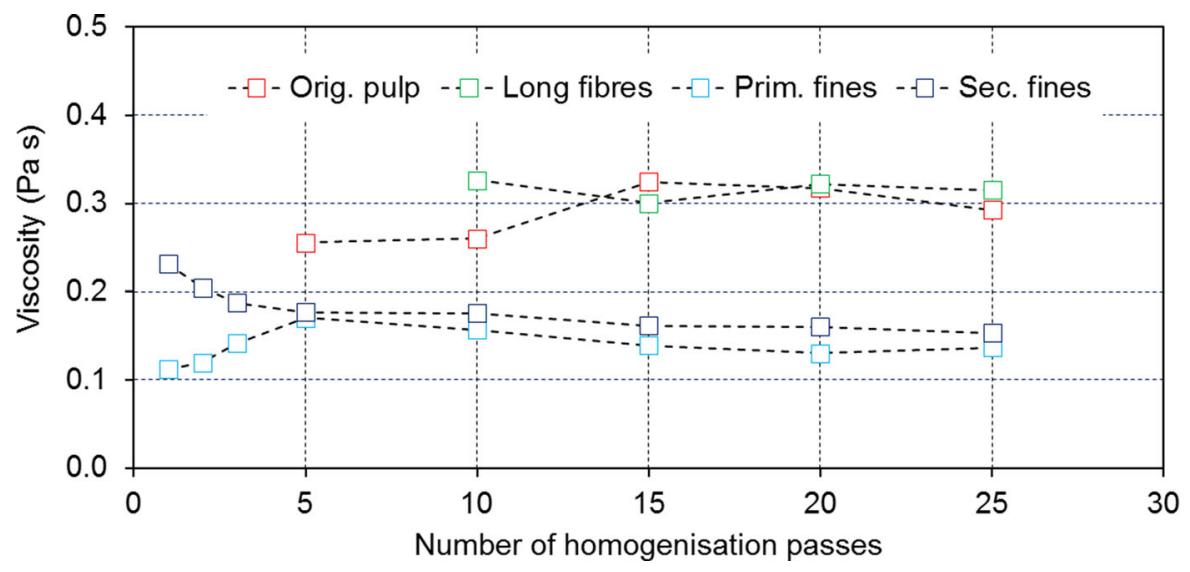

Fig. 5 Viscosity of original pulp and different pulp fractions after different numbers of passes through the high pressure homogeniser 

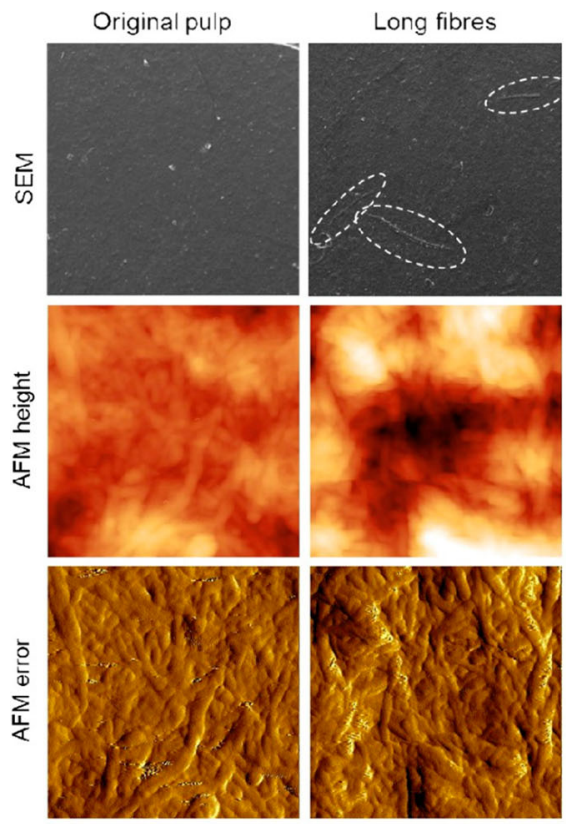

Fig. 6 SEM and AFM images of nanopaper surfaces produced from original pulp and different fractions thereof. Dotted circles highlights large fibre residues. The inset in the SEM image of the

material, differences in microfibril angle of individual cell wall layers as well may contribute to the formation of the observed plate like structures.

In good agreement with a high degree of fibrillation already indicated in SEM images, AFM reveals surface topography typical of highly fibrillated pulp. As far as this can be ascertained from topography images, typical fibril diameters are $<50 \mathrm{~nm}$ and smaller. Same as for fibril diameter, the surface structure of nanopapers produced from the individual pulp fractions did not show clear differences.

Finally, the mechanical performance of nanopapers was evaluated by means of tensile tests (Fig. 7; Table 2). All nanopapers typically show a short phase of linear elastic behaviour and, after a yield point at around 1\% strain, a distinct plastic phase (Fig. 7). Interestingly, only the nanopaper derived from the original pulp also shows clear strain hardening as visible in the upward curvature of the stress strain graph in the plastic region.

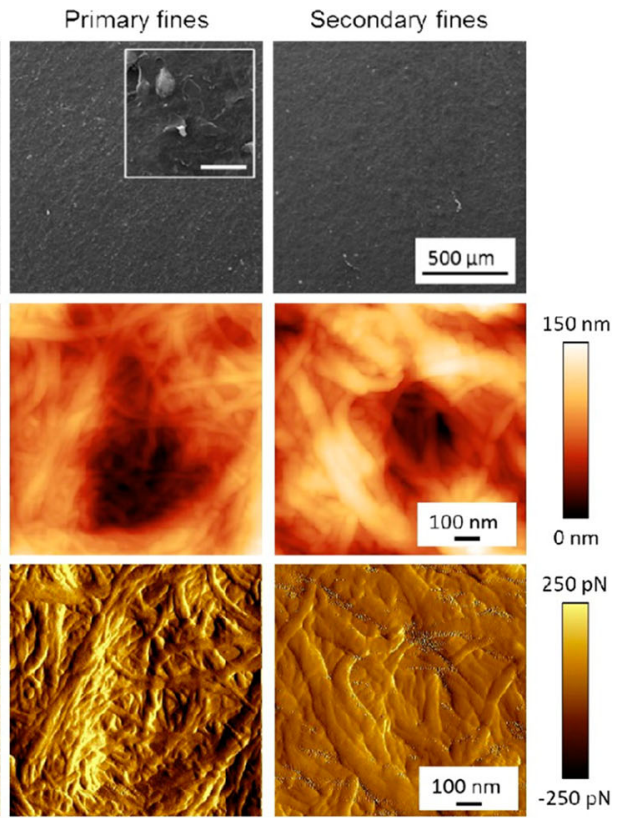

primary fines section shows a high magnification image (bar $=5 \mu \mathrm{m})$. The AFM error image derives from the feedback system, which controls the tip movement

The mechanical performance of nanopapers derived from different pulp fractions is summarised in Table 2. By comparison with literature (GindlAltmutter et al. 2012; Henriksson et al. 2008) the modulus of elasticity of cellulose nanopaper is typically in the order of $10 \mathrm{GPa}$, tensile strength $>200$ $\mathrm{MPa}$ and elongation around $10 \%$. This also applies to materials tested in the present study, with some minor exceptions. On the one hand, CNF nanopapers derived from original pulp and secondary fines, respectively, show best performance in terms of strength and elongation, but their modulus of elasticity remains below $8 \mathrm{GPa}$. On the other hand, CNFs derived from primary fines yields the highest modulus $(9.3 \mathrm{GPa})$ but lowest elongation at break $(6.3 \%)$. Even though, having the smallest particle size distribution, this indicates imperfections deriving from small cell wall particles in the material as mentioned before. 

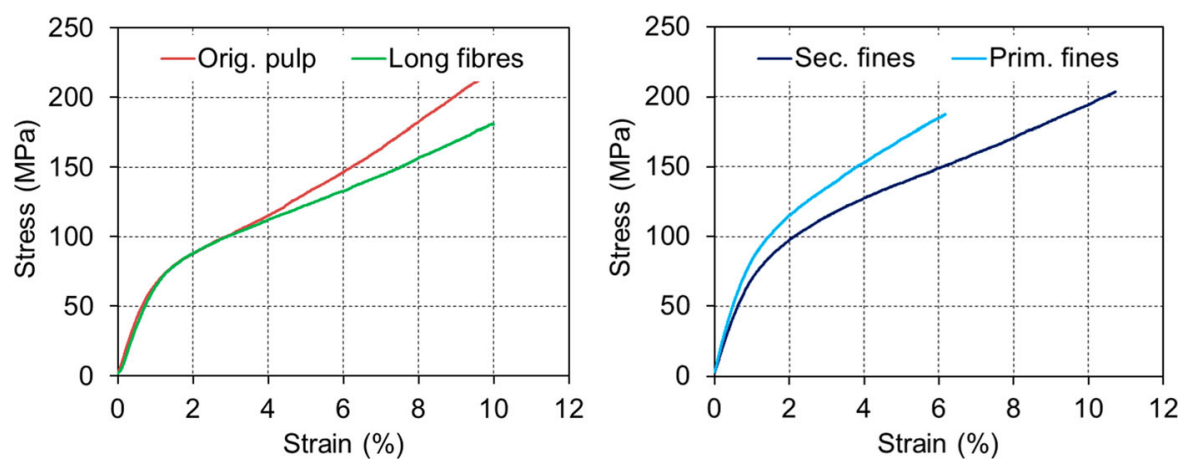

Fig. 7 Typical stress-strain curves from tensile tests with nanopapers produced from original pulp and different fractions thereof

Table 2 Results of tensile tests (10 specimens each) with CNF nanopapers produced from different pulp fractions after 20 homogenisation passes ( $\mathrm{E}$ modulus of elasticity, $\sigma$ tensile strength, $\varepsilon$ elongation at break)

\begin{tabular}{llll}
\hline Fibre type & $\mathrm{E}(\mathrm{GPa})$ & $\sigma(\mathrm{MPa})$ & $\varepsilon(\%)$ \\
\hline Original pulp & $7.1 \pm 0.45$ & $213 \pm 33.5$ & $9.8 \pm 2.09$ \\
Long fibres & $6.7 \pm 0.48$ & $174 \pm 34.9$ & $9.8 \pm 2.37$ \\
Primary fines & $9.3 \pm 0.31$ & $185 \pm 12.1$ & $6.3 \pm 1.13$ \\
Secondary fines & $7.7 \pm 0.31$ & $201 \pm 21.1$ & $10.0 \pm 1.57$ \\
\hline
\end{tabular}

\section{Conclusions}

Overall, the results of the present study demonstrate that the use of fines instead of long pulp fibres for the production of CNFs does not show a negative impact on CNFs quality. By comparison, the average aggregate size of fines-derived CNFs is smaller than is the case for CNFs derived from regular long fibres and pulp, resulting also in lower viscosity in suspension. Since AFM measurements show comparable fibril diameters, the reason for reduced viscosity is most probably reduced overall fibril length. Notably, after 5 homogenisation passes the disintegration kinetics diminishes, which could be useful for upscaling CNF production. Resulting in lower energy consumption compared to production processes involving original and long fibre pulp fractions. Nonetheless, mechanical CNF nanopaper performance is similar for all variants (fines- or long fibre-derived), with primary fines nanopaper showing high stiffness at comparably low elongation, and secondary fines nanopaper performing well in terms of high strength and elongation. Consequently, the fines fraction of sulfite pulp is deemed a technically highly suitable raw material for CNF production.

Acknowledgments Funding provided by our industry partners in the frame of the FLIPPR ${ }^{2}$ project (FFG project 861476), Mondi, Sappi, Zellstoff Pöls AG and Papierholz Austria is gratefully acknowledged. The K-Project FLIPPR ${ }^{2}$ is funded as part of COMET-Competence Centers for Excellent Technologies promoted by BMVIT, BMWFW, Styria and Carinthia. The COMET program is managed by the Austrian Research Promotion Agency FFG.

Funding Open access funding provided by University of Natural Resources and Life Sciences Vienna (BOKU).

\section{Compliance with ethical standards}

Conflict of interest The authors declare that they have no conflict of interest.

Open Access This article is licensed under a Creative Commons Attribution 4.0 International License, which permits use, sharing, adaptation, distribution and reproduction in any medium or format, as long as you give appropriate credit to the original author(s) and the source, provide a link to the Creative Commons licence, and indicate if changes were made. The images or other third party material in this article are included in the article's Creative Commons licence, unless indicated otherwise in a credit line to the material. If material is not included in the article's Creative Commons licence and your intended use is not permitted by statutory regulation or exceeds the permitted use, you will need to obtain permission directly from the copyright holder. To view a copy of this licence, visit http://creativecommons.org/licenses/by/4.0/.

\section{References}

Agate S, Joyce M, Lucia L, Pal L (2018) Cellulose and nanocellulose-based flexible-hybrid printed electronics and conductive composites-a review. Carbohydr Polym 
198:249-260. https://doi.org/10.1016/j.carbpol.2018.06. 045

Ansari F, Berglund LA (2018) Toward semistructural cellulose nanocomposites: the need for scalable. Process Interface Tailoring Biomacromol 19:2341-2350. https://doi.org/10. 1021/acs.biomac. 8 b00142

Bharimalla AK, Deshmukh SP, Vigneshwaran N, Patil PG, Prasad V (2017) Nanocellulose-polymer composites for applications in food packaging: current status, future prospects and challenges. Polym Plast Technol 56:805-823. https://doi.org/10.1080/03602559.2016.1233281

Bossu J, Czibula CV, Winter A, Gindl-Altmutter W, Eckhart R, Zankel A, Bauer W Combined effect of the morphology and rate of addition of fine cellulosic materials produced from chemical pulp on paper properties. In: International paper physics conference: held in conjunction with PaperCon2019, 2019. Tappi Press, pp 247-259

Boufi S, González I, Delgado-Aguilar M, Tarrès Q, Pèlach M, Mutjé P (2016) Nanofibrillated cellulose as an additive in papermaking process: a review. Carbohydr Polym 154:151-166. https://doi.org/10.1016/j.carbpol.2016.07. 117

Charreau H, Foresti ML, Vázquez A (2013) Nanocellulose patents trends: a comprehensive review on patents on cellulose nanocrystals, microfibrillated and bacterial cellulose. Recent Pat Nanotech 7:56-80

Colson J, Amer H, Liebner F, Gindl-Altmutter W (2018) Oilabsorbing porous cellulosic material from sized wood pulp fines. Holzforschung 73:83-92

Colson J, Bauer W, Mayr M, Fischer W, Gindl-Altmutter W (2016) Morphology and rheology of cellulose nanofibrils derived from mixtures of pulp fibres and papermaking fines. Cellulose 23:2439-2448. https://doi.org/10.1007/ s10570-016-0987-x

Colson J, Kovalcik A, Kucharczyk P, Gindl-Altmutter W (2017) Reinforcement of Poly (Lactic Acid) with Spray-dried. Lignocellul Mater Bioresour 12:1112-1127. https://doi. org/10.15376/biores.12.1.1112-1127

Cypriano DZ, da Silva LL, Tasic L (2018) High value-added products from the orange juice industry waste. Waste Manage 79:71-78. https://doi.org/10.1016/j.wasman.2018. 07.028

Dai L et al (2019) 3D printing using plant-derived cellulose and its derivatives: a review. Carbohydr Polym 203:71-86. https://doi.org/10.1016/j.carbpol.2018.09.027

Desmaisons J, Boutonnet E, Rueff M, Dufresne A, Bras J (2017) A new quality index for benchmarking of different cellulose nanofibrils. Carbohydr Polym 174:318-329. https:// doi.org/10.1016/j.carbpol.2017.06.032

Du H, Liu W, Zhang M, Si C, Zhang X, Li B (2019) Cellulose nanocrystals and cellulose nanofibrils based hydrogels for biomedical applications. Carbohydr Polym 209:130-144. https://doi.org/10.1016/j.carbpol.2019.01.020

Dufresne A (2013) Nanocellulose: a new ageless bionanomaterial. Mater Today 16:220-227. https://doi.org/10.1016/j. mattod.2013.06.004

Dumanli AG (2017) Nanocellulose and its composites for biomedical applications. Curr Med Chem 24:512-528. https://doi.org/10.2174/0929867323666161014124008
Eichhorn SJ et al (2010) Review: current international research into cellulose nanofibres and nanocomposites. J Mater Sci 45:1-33. https://doi.org/10.1007/s10853-009-3874-0

Ferrer A, Pal L, Hubbe M (2017) Nanocellulose in packaging: advances in barrier layer technologies. Ind Crop Prod 95:574-582. https://doi.org/10.1016/j.indcrop.2016.11. 012

Fischer WJ et al (2017) Pulp fines-characterization, sheet formation, and comparison to microfibrillated. Cellul Polym. https://doi.org/10.3390/polym9080366

De France KJ, Hoare T, Cranston ED (2017) Review of hydrogels and aerogels containing. Nanocellul Chem Mater 29:4609-4631. https://doi.org/10.1021/acs. chemmater.7b00531

Gan I, Chow WS (2018) Antimicrobial poly(lactic acid)/cellulose bionanocomposite for food packaging application: a review. Food Packag Shelf Life 17:150-161. https://doi. org/10.1016/j.fpsl.2018.06.012

Gindl-Altmutter W, Veigel S, Obersriebnig M, Tippelreither C, Keckes J (2012) High-modulus oriented cellulose nanopaper vol 1107. ACS Sym Ser. https://doi.org/10. 1021/bk-2012-1107.ch001

Grueneberger F, Kuenniger T, Zimmermann T, Arnold M (2014) Rheology of nanofibrillated cellulose/acrylate systems for coating applications. Cellulose 21:1313-1326. https://doi.org/10.1007/s10570-014-0248-9

Henniges U, Veigel S, Lems EM, Bauer A, Keckes J, Pinkl S, Gindl-Altmutter W (2014) Microfibrillated cellulose and cellulose nanopaper from Miscanthus biogas production residue. Cellulose 21:1601-1610. https://doi.org/10.1007/ s10570-014-0232-4

Henriksson M, Berglund LA, Isaksson P, Lindström T, Nishino $\mathrm{T}$ (2008) Cellulose nanopaper structures of high toughness. Biomacromolecules 9:1579-1585. https://doi.org/10.1021/ bm800038n

Hietala M, Sain S, Oksman K (2017) Highly redispersible sugar beet nanofibers as reinforcement in bionanocomposites. Cellulose 24:2177-2189. https://doi.org/10.1007/s10570017-1245-6

Hyll K (2015) Size and shape characterization of fines and fillers: a review Nord Pulp. Paper Res J 30:466-487

ISO (2014) Pulps-Determination of fibre length by automated optical analysis - Part 2: Unpolarized light method vol 16065-2

Iotti M, Gregersen OW, Moe S, Lenes M (2011) Rheological studies of microfibrillar cellulose water dispersions. J Polym Environ 19:137-145. https://doi.org/10.1007/ s10924-010-0248-2

Kargarzadeh H et al (2018) Recent developments in nanocellulose-based biodegradable polymers, thermoplastic polymers, and porous nanocomposites. Prog Polym Sci 87:197-227. https://doi.org/10.1016/j.progpolymsci.2018. 07.008

Klemm D et al (2018) Nanocellulose as a natural source for groundbreaking applications in materials science: today's state. Mater Today 21:720-748. https://doi.org/10.1016/j. mattod.2018.02.001

Lee K-Y, Aitomäki Y, Berglund LA, Oksman K, Bismarck A (2014) On the use of nanocellulose as reinforcement in polymer matrix composites. Compos Sci Technol 
105:15-27. https://doi.org/10.1016/j.compscitech.2014. 08.032

Leitner J, Hinterstoisser B, Wastyn M, Keckes J, Gindl W (2007) Sugar beet cellulose nanofibril-reinforced composites. Cellulose 14:419-425. https://doi.org/10.1007/ s10570-007-9131-2

Long L-Y, Weng Y-X, Wang Y-Z (2018) Cellulose aerogels: synthesis, applications, and prospects. Polymers 10:623

Mathew AP, Oksman K, Karim Z, Liu P, Khan SA, Naseri N (2014) Process scale up and characterization of wood cellulose nanocrystals hydrolysed using bioethanol pilot plant. Ind Crop Prod 58:212-219. doi:https://doi.org/10. 1016/j.indcrop.2014.04.035

Mayr M, Eckhart R, Bauer W (2017) Improved microscopy method for morphological characterisation of pulp fines Nord Pulp Paper Res J 32:244-252

Odabas N, Henniges U, Potthast A, Rosenau T (2016) Cellulosic fines: properties and effects. Prog Mater Sci 83:574-594. https://doi.org/10.1016/j.pmatsci.2016.07.006

Oksman K et al (2016) Review of the recent developments in cellulose nanocomposite processing. Compos Part A-Appl S 83:2-18. https://doi.org/10.1016/j.compositesa.2015.10. 041

Osong SH, Norgren S, Engstrand P (2015) Processing of woodbased microfibrillated cellulose and nanofibrillated cellulose, and applications relating to papermaking: a review. Cellulose 23:93-123. https://doi.org/10.1007/s10570-0150798-5

Phanthong P, Reubroycharoen P, Hao X, Xu G, Abudula A, Guan G (2018) Nanocellulose: extraction and application. Carbon Resour Convers 1:32-43. https://doi.org/10.1016/j. crcon.2018.05.004

Rajinipriya M, Nagalakshmaiah M, Robert M, Elkoun S (2018) Importance of agricultural and industrial waste in the field of nanocellulose and recent industrial developments of wood based nanocellulose: a review. ACS Sustain Chem Eng 6:2807-2828. https://doi.org/10.1021/acssuschemeng. $7 \mathrm{~b} 03437$

Shahabi-Ghahafarrokhi I, Khodaiyan F, Mousavi M, Yousefi H (2015) Preparation and characterization of nanocellulose from beer industrial residues using acid hydrolysis/ultrasound. Fiber Polym 16:529-536. https://doi.org/10.1007/ s12221-015-0529-4

Siddiqui N, Mills RH, Gardner DJ, Bousfield D (2011) Production and characterization of cellulose nanofibers from wood pulp. J Adhes Sci Technol 25:709-721. https://doi. org/10.1163/016942410x525975

Siqueira G et al (2017) Cellulose nanocrystal inks for 3D printing of textured cellular architectures. Adv Funct Mater 27:1604619. https://doi.org/10.1002/adfm.201604619

Spence KL, Venditti RA, Rojas OJ, Habibi Y, Pawlak JJ (2011) A comparative study of energy consumption and physical properties of microfibrillated cellulose produced by different processing methods. Cellulose 18:1097-1111. https://doi.org/10.1007/s10570-011-9533-Z

Tao P, Wu Z, Xing C, Zhang Q, Wei Z, Nie S (2019) Effect of enzymatic treatment on the thermal stability of cellulose nanofibrils. Cellulose 26:7717-7725. https://doi.org/10. 1007/s10570-019-02634-3

Tejado A, Alam MN, Antal M, Yang H, van de Ven TGM (2012) Energy requirements for the disintegration of cellulose fibers into cellulose nanofibers. Cellulose 19:831-842. https://doi.org/10.1007/s10570-012-9694-4

Thomas B et al (2018) Nanocellulose, a versatile green platform: from biosources to materials and their applications. Chem Rev 118:11575-11625. https://doi.org/10.1021/acs. chemrev.7b00627

Turbak AF, Snyder FW, Sandberg KR (1983) Microfibrillated cellulose, a new cellulose product: properties, uses, and commercial potential. Journal Name: J Appl Polym Sci Appl Polym Symp (United States); Journal Volume: 37; Conference: 9. cellulose conference, Syracuse, NY, USA, 24 May 1982.; ITT Rayonier Inc., Shelton, WA

Xing J, Tao P, Wu Z, Xing C, Liao X, Nie S (2019) Nanocellulose-graphene composites: a promising nanomaterial for flexible supercapacitors. Carbohydr Polym 207:447-459. https://doi.org/10.1016/j.carbpol.2018.12.010

Xu W, Wang X, Sandler N, Willför S, Xu C (2018) Threedimensional printing of wood-derived biopolymers: a review focused on biomedical applications. ACS Sustain Chem Eng 6:5663-5680. https://doi.org/10.1021/ acssuschemeng.7b03924

Yang Q, Zhang C, Shi Z, Wang J, Xiong C, Saito T, Isogai A (2018) Luminescent and transparent nanocellulose films containing Europium carboxylate groups as flexible dielectric materials. ACS Appl Nano Mater 1:4972-4979. https://doi.org/10.1021/acsanm.8b01112

Zhang N, Tao P, Lu Y, Nie S (2019) Effect of lignin on the thermal stability of cellulose nanofibrils produced from bagasse pulp. Cellulose 26:7823-7835. https://doi.org/10. 1007/s10570-019-02657-w

Zhang K, Zhang Y, Yan D, Zhang C, Nie S (2018) Enzymeassisted mechanical production of cellulose nanofibrils: thermal stability. Cellulose 25:5049-5061. https://doi.org/ 10.1007/s10570-018-1928-7

Zu G, Shen J, Zou L, Wang F, Wang X, Zhang Y, Yao X (2016) Nanocellulose-derived highly porous carbon aerogels for supercapacitors. Carbon 99:203-211. https://doi.org/10. 1016/j.carbon.2015.11.079

Publisher's Note Springer Nature remains neutral with regard to jurisdictional claims in published maps and institutional affiliations. 